\title{
Foreword special issue on cloud computing and services science
}

\author{
Markus Helfert $^{1}$ • Donald Ferguson ${ }^{2}$. \\ Víctor Méndez Muñoz ${ }^{3}$
}

This Special Issue on Cloud Computing and Services Science is the result of a free competition call. Together with the open call, the editors invited to submit extended versions from best contributions to CLOSER 2015 (the 5th International Conference on Cloud Computing and Services Science), held in Lisbon, Portugal, in 2015, organized and sponsored by the Institute for Systems and Technologies of Information, Control and Communication (INSTICC). This conference was held in Cooperation with the Association for Computing Machinery - Special Interest Group on Management Information Systems and Turismo de Lisboa. The CLOSER 2015 bests contributions were invited by the scores of the reviewers, the presentations scores from conference delegates, as well as a selection of papers holding potential extension of interest in at least a $30 \%$ of new content with significant advances in validation, modeling or contributions.

We received an overall of 20 submissions in free competition. The papers were peer reviewed to the professional and scientific standards expected of the Computing journal published by Springer. Papers were assessed according to the journal's Peer

\footnotetext{
$凶 \quad$ Markus Helfert

markus.helfert@dcu.ie

Donald Ferguson

donald.ferguson@sparq.tv

Víctor Méndez Muñoz

victor.mendez@uab.es

1 Dublin City University, Dublin, Ireland

2 Columbia University, New York, NY, USA

3 Department of Computer Architecture and Operating Systems (CAOS), Area of Computer Architecture and Technology, Edifici Q, Campus de la UAB, 08193 Bellaterra

(Cerdanyola del Vallès), Barcelona, Spain
} 
Review Policy which judges papers on aspects including scientific merit (notably scientific rigour, accuracy and correctness), clarity of expression and originality. This Special Issue presents 8 papers which have been accepted for publication after this toughly review process.

We expect that this special issue will interest to the CLOSER community in lato sensu: conference participants, potential participants, readers, engineers, scientists and business people interested in cloud computing and service systems. We further believe that the papers in this Special Issue demonstrate new and innovative solutions, and highlight technical problems in challenging areas like "Cloud Computing Fundamentals", "Services Science Foundation for Cloud Computing", "Cloud Computing Platforms and Applications", "Cloud Computing Enabling Technology" and "Mobile Cloud Computing and Services".

We wish to thank all those who supported and helped to publish this Special Issue. We would like to thank the authors, whose work mostly contributed to a free competition, also to the authors which work has not been accepted, encouraging them to improve and contribute again in the Computing Journal and in the CLOSER community calls, thanks the reviewers of the Special issue, whose expertise and diligence were instrumental to ensure the quality of final contributions. We also wish to thank all the members of the CLOSER Organizing Committee whose work and commitment was invaluable supporting this Special Isue. Last but not least, we would like to thank Prof. Dustdar for his kindly support as Chief Editor, and the Computing Journal editorial team for their collaboration in getting this Special Issue to print. 